\title{
Targeted drug discovery for pediatric leukemia
}

\section{Andrew D. Napper * and Venita G. Watson ${ }^{\dagger}$}

High-Throughput Screening and Drug Discovery Laboratory, Nemours Center for Childhood Cancer Research, A.I. duPont Hospital for Children, Wilmington, DE, USA

Edited by:

Jeffrey Toretsky, Georgetown

University, USA

Reviewed by:

Charles S. Hemenway, Loyola

University Chicago Stritch School of

Medicine, USA

Rachel Rau, Baylor College of

Medicine, USA

${ }^{*}$ Correspondence:

Andrew D. Napper, High-Throughput Screening and Drug Discovery

Laboratory, Nemours Center for

Childhood Cancer Research, A.I.

duPont Hospital for Children, 1701

Rockland Road, Wilmington, DE

19803, USA

e-mail: napper@nemoursresearch.org

\section{${ }^{\dagger}$ Present address:}

Venita G. Watson, Constellation

Pharmaceuticals, Cambridge, MA,

USA
Despite dramatic advances in the treatment of pediatric leukemia over the past 50 years, there remain subsets of patients who respond poorly to treatment. Many of the high-risk cases of childhood leukemia with the poorest prognosis have been found to harbor specific genetic signatures, often resulting from chromosomal rearrangements. With increased understanding of the genetic and epigenetic makeup of high-risk pediatric leukemia has come the opportunity to develop targeted therapies that promise to be both more effective and less toxic than current chemotherapy. Of particular importance is an understanding of the interconnections between different targets within the same cancer, and observations of synergy between two different targeted therapies or between a targeted drug and conventional chemotherapy. It has become clear that many cancers are able to circumvent a single specific blockade, and pediatric leukemias are no exception in this regard. This review highlights the most promising approaches to new drugs and drug combinations for high-risk pediatric leukemia. Key biological evidence supporting selection of molecular targets is presented, together with a critical survey of recent progress toward the discovery, pre-clinical development, and clinical study of novel molecular therapeutics.

Keywords: drug discovery, targeted therapy, leukemia, molecular target, medicinal chemistry, lead optimization

\section{PEDIATRIC LEUKEMIA: THE NEED FOR TARGETED THERAPIES}

This review focuses on pediatric leukemia, both acute lymphoblastic leukemia (ALL) and acute myeloid leukemia (AML), which together account for approximately one third of childhood cancers. ALL is primarily a childhood disease, whereas AML is much more prevalent in adults (National Cancer Institute, 2010). However, due to its poorer prognosis, AML accounts for as many childhood deaths per year as ALL. Aggressive treatment of children with combinations of cytotoxic drugs has raised the 5-year survival rate for pediatric ALL above $80 \%$. Given that less than one child in 10 survived ALL in the early 1960s, this is a remarkable achievement. However, this progress has come at the cost of severe toxicity, and nearly $20 \%$ of ALL cases either do not respond or relapse following treatment. The 5-year survival rate for pediatric AML is under $60 \%$. AML that arises following treatment for another malignancy (therapy-related AML) is particularly difficult to cure (Kurmasheva and Houghton, 2007; Pui et al., 2011b). Figure 1 highlights how progress has slowed following a dramatic improvement in survival from the 1950s-1980s.

In the past 30 years, few new anti-cancer agents have been approved for use in pediatric patients. Survival in very high-risk patient groups remains poor despite the most intensive cytotoxic therapies. Rationally designed drugs have benefited adults with cancer, but except in the case of BCR-ABL positive leukemias, targeted therapies have so far done little to improve pediatric outcomes. However, there are encouraging signs that this situation is about to change. Study of the mechanistic basis for pediatric cancer has begun to uncover defined molecular targets, raising the possibility of treatment by specifically designed drugs (Mackall, 2011). In most cases of pediatric leukemia, the genetic profile is well-defined, and patients at high risk of poor response to treatment may be readily identified. However, this characterization of leukemia by subtype generally has not led to much improvement in outcome, due to an inability to develop effective new drugs because of a lack of understanding of the biological mechanisms connecting specific genetic abnormalities and leukemia progression (Pui et al., 2011a). Readers are referred to recent reviews (Brandwein, 2011; Pui et al., 2011b) for current treatment regimens and clinical outcomes. A notable exception to the dismal lack of success in treating high-risk leukemia in children has been the remarkable efficacy of the BCR-ABL kinase inhibitor imatinib (Gleevec) in Philadelphia-positive $\left(\mathrm{Ph}^{+}\right)$ALL (Barr, 2010). In recent years other points of intervention have been identified that may respond to targeted drugs. This review highlights the biological evidence pointing to novel specific molecular targets and the progress of drug discovery efforts based on this evidence, especially for some of the most intractable high-risk subtypes of ALL and AML.

\section{MOLECULARLY TARGETED DRUG DISCOVERY AND DEVELOPMENT}

The approval of imatinib in 2001 to treat chronic myeloid leukemia (CML) and its remarkable success rate - 90\% 5-year survival spurred efforts to develop additional molecularly targeted therapies for cancer and other diseases. The majority of this effort has been directed toward adult disease, but an increased understanding of the biology of pediatric cancer has fostered progress toward targeted treatment of some of the most intractable cases (Brown et al., 2009). The NCI lists 207 treatment clinical trials ongoing for pediatric ALL and 188 for AML. (Note that the total number is substantially less than 395 because trials for both ALL and AML are 


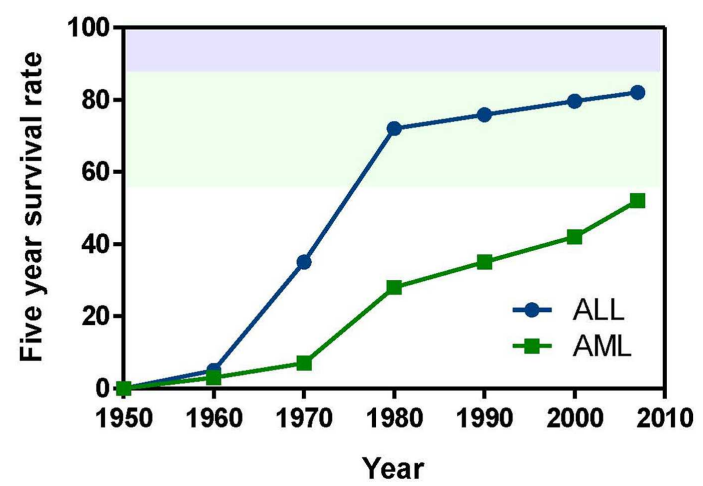

FIGURE 1 | Pediatric leukemia survival trends from 1950 to the present. Data obtained from Kersey (1997) and Pui et al. (2011b).

counted twice.) Of these, 26 (13 both ALL and AML, 10 ALL and 3 AML) are testing molecularly targeted agents (National Cancer Institute, 2013). Numerous compound series are in earlier stages of lead optimization and pre-clinical development. This review is organized by broad disease targeting mechanisms, and further subdivided by protein target classes. Numbers in bold type in parentheses after compound names may be used to locate compounds in Table 1, which summarizes the current roster of clinical candidates and references the clinical protocol IDs (National Cancer Institute, 2013). The bold-type compound numbers also will help the reader locate molecular structures depicted in Figures 2 and 3. Sections "Cell Proliferation and Apoptosis, Transcription, and Chemokine Receptors and Stem Cell Homing" cover candidates in clinical trials and highlight the most recent and innovative examples of compounds in early discovery and pre-clinical development. Several recent reviews cover specific targets and pathways, and the reader is referred to these for more comprehensive coverage. Although a majority of the agents under development are aimed at arrest of cell proliferation and induction of apoptosis, substantial work is also focused on modulation of transcription, and homing of stem cells to the bone marrow.

\section{CELL PROLIFERATION AND APOPTOSIS}

Development of protein kinase inhibitors as therapeutic agents for adult cancer has been an area of intense effort for many years. Likewise, certain protein kinases in pediatric acute leukemia have been targeted because they mediate cell signaling that promotes growth and resists apoptosis. The most notable success has been the inhibition of BCR-ABL, while much attention continues to be focused on the receptor tyrosine kinase (RTK) FMS-like tyrosine kinase-3 (FLT3), the mTOR/AKT pathway, JAK/STAT signaling, and control of mitosis by aurora kinases (Figure 4). In addition to protein kinases, the proteasome, and the anti-apoptotic protein BCL-2 are being targeted for inhibition to induce apoptosis in pediatric leukemia.

\section{Protein tyrosine kinases}

$\boldsymbol{B C R}-\boldsymbol{A B L}$. The first example of a molecularly targeted therapy for cancer was imatinib (1) (Gleevec), an inhibitor of the ABL tyrosine kinase activity of the fusion protein BCR-ABL. This was initially developed to treat CML in adults, but has since been shown to be highly effective against $\mathrm{Ph}^{+}$ALL in children, which also harbors the BCL-ABL fusion (Schultz et al., 2009; Barr, 2010), and it was recently approved by the FDA for this indication (Food and Drug Administration, 2013). Since use of imatinib in children began, the 5-year survival rate for pediatric $\mathrm{Ph}^{+}$ALL has more than doubled to $80 \%$. However, the appearance of mutant forms of the kinase domain of BCR-ABL has led to resistance to imatinib (Hunger, 2011). Therefore, new series of inhibitors have been developed to target mutant forms of the enzyme as well as the wild type. Dasatinib (2) is currently in two Phase II trials for pediatric $\mathrm{Ph}^{+} \mathrm{ALL}$. Nilotinib (3) binds 30 -fold more tightly than imatinib to BCL-ABL in resistant leukemia cells and is currently in Phase I pediatric trials. However, neither dasatinib nor nilotinib are effective against so-called gatekeeper mutations, notably T315I. This shortcoming has been overcome by structure-based design of ponatinib, which gave encouraging Phase I results in adult CML and $\mathrm{Ph}^{+}$ ALL (Cortes et al., 2012). A Phase II trial of ponatinib in $\mathrm{Ph}^{+}$ALL is due to start soon, but enrollment is limited to adult patients. (See Figure 2A for structures of the compounds discussed in this section.)

FLT3 and other RTKs. Receptor tyrosine kinases play an important signal transduction role in acute leukemia. The FLT3 gene is mutated in a significant proportion of high-risk pediatric ALL and AML; activating FLT3 mutations occur in $22 \%$ of AML and $18 \%$ of MLL-rearranged ALL. AML harboring FLT3 internal tandem duplications (FLT3-ITD) is associated with an especially poor prognosis (Brown et al., 2006; Stubbs and Armstrong, 2007; Swords et al., 2012). FLT3 mutations promote leukemia survival and proliferation and block cell differentiation (Sexauer et al., 2012). So far, FLT3 inhibitors have shown limited effectiveness as single agent therapies, due to several confounding factors: low plasma levels of compounds due to poor pharmacokinetics, limited efficacy due to high levels of competing FLT3 ligand (FL), and point mutations arising in the inhibitor binding pocket (Grunwald and Levis, 2013). Intense effort is focused on optimizing clinical response through design of improved compounds, adjustment of dosage of conventional chemotherapy to attenuate $\mathrm{FL}$ levels, and development of combination therapies. Currently, compounds are in clinical trials as therapies to treat MLL-rearranged leukemia (ALL and AML) and AML harboring FLT3-ITD (Daver and Cortes, 2012). The staurosporine analog Lestaurtinib (4) is being tested in MLL-rearranged infant ALL in a multicenter Phase III trial in combination with conventional chemotherapy. A Phase I/II dose-ranging trial of Midostaurin (5), another analog of the natural product staurosporine, is ongoing in pediatric ALL and AML. Other structural classes are also being tested. Sorafenib (6), originally developed as a B-RAF inhibitor, also inhibits FLT3 and is selectively cytotoxic to leukemia cells harboring FLT3 mutations. It is currently in a Phase III trial in AML, as well as a Phase I trial in combination with conventional chemotherapy. The most potent FLT3 inhibitor in cells harboring FLT3-ITD is quizartinib (7), with an IC $_{50}$ of $1 \mathrm{nM}$ (Kampa-Schittenhelm et al., 2013). It is currently in a Phase I trial in relapsed or refractory ALL and AML. A recent report describes BPR1J-097 (8), a FLT3 inhibitor in pre-clinical development with selectivity and in vivo pharmacokinetics that 
Table 1 | Compounds currently in clinical trials as targeted drugs in pediatric ALL or AML.

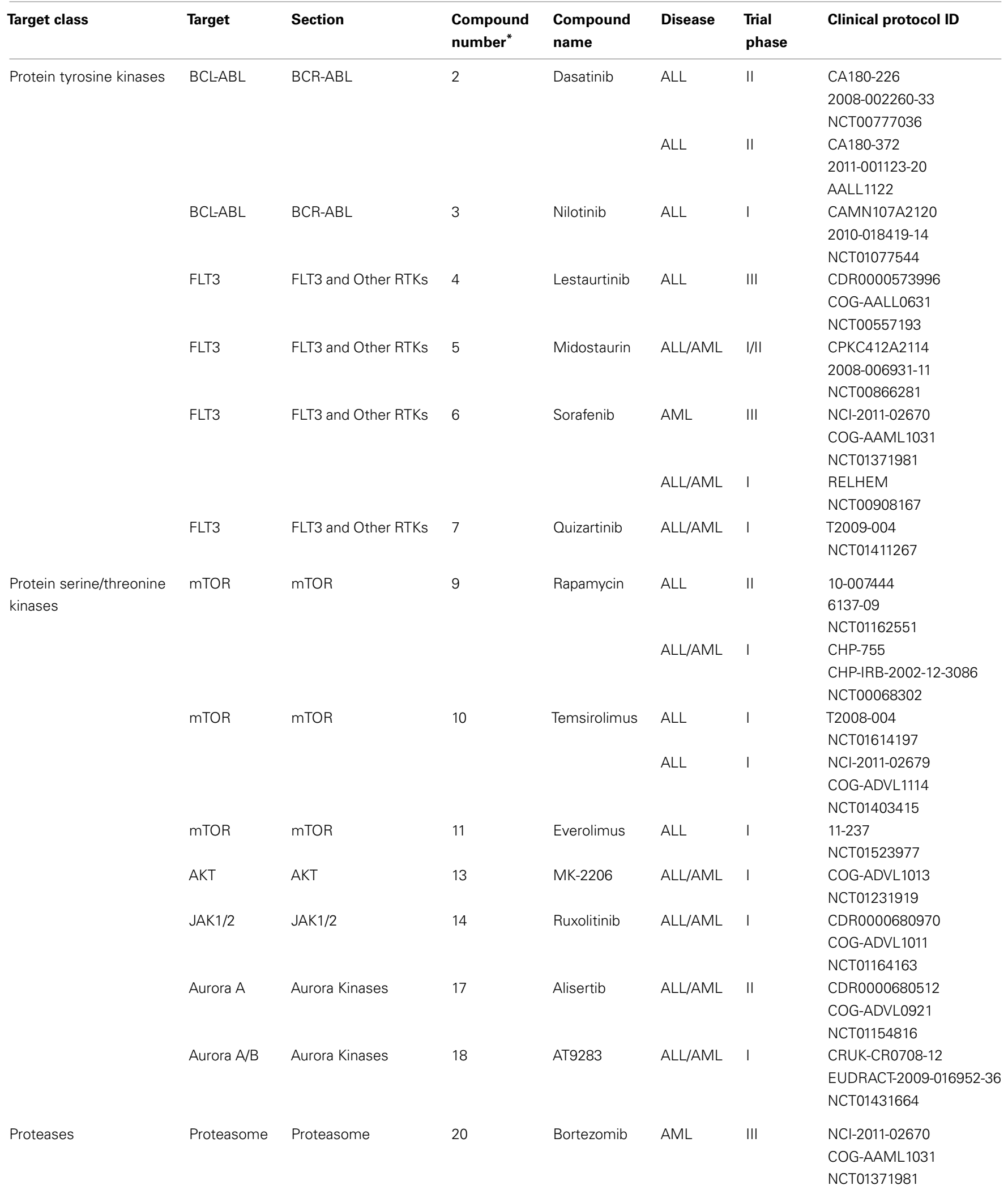


Table 1 | Continued

\begin{tabular}{|c|c|c|c|c|c|c|c|}
\hline Target class & Target & Section & $\begin{array}{l}\text { Compound } \\
\text { number }\end{array}$ & $\begin{array}{l}\text { Compound } \\
\text { name }\end{array}$ & Disease & $\begin{array}{l}\text { Trial } \\
\text { phase }\end{array}$ & Clinical protocol ID \\
\hline & & & & & ALL & $\|$ & 2008LS113 \\
\hline & & & & & & & MT2008-33R \\
\hline & & & & & & & NCT01312818 \\
\hline & & & & & ALL & $\|$ & CDR0000638413 \\
\hline & & & & & & & COG-AALL07P1 \\
\hline & & & & & & & NCT00873093 \\
\hline \multirow[t]{2}{*}{ Anti-apoptotic proteins } & $\mathrm{Bcl}-2$ & Anti-Apoptotic & 23 & Obatoclax & ALL/AML & I & COG-ADVL0816 \\
\hline & & Protein BCL-2 & & & & & NCT00933985 \\
\hline \multirow{3}{*}{$\begin{array}{l}\text { DNA } \\
\text { methyltransferases }\end{array}$} & Various & DNA & 24 & 5-Azacytidine & AML & $\|$ & J1240 \\
\hline & & Methyltransferases & & & & & P01CA015396 \\
\hline & & & & & & & NCT01700673 \\
\hline \multirow[t]{7}{*}{ Histone deacetylases } & Various & Histone & 28 & Vorinostat & ALL/AML & II & NCT-2007-11-02-1004 \\
\hline & & Deacetylases & & & & & NCT01422499 \\
\hline & Various & Histone & 29 & Panobinostat & ALL/AML & 1 & T2009-012 \\
\hline & & Deacetylases & & & & & NCT01321346 \\
\hline & Various & Histone & 30 & AR-42 & AML & । & OSU-11130 \\
\hline & & Deacetylases & & & & & NCl-2013-00122 \\
\hline & & & & & & & NCT01798901 \\
\hline \multirow[t]{3}{*}{ Chemokine receptors } & CXCR4 & Chemokine & 37 & Plerixafor & ALL/AML & I & POETIC Plerixafor \\
\hline & & Receptors and Stem & & & & & NCT01319864 \\
\hline & & Cell Homing & & & & & \\
\hline
\end{tabular}

${ }^{*}$ Refers to compound number in text and in Figures 2 and $\mathbf{3}$.

are apparently superior to those of earlier compound classes (Lin et al., 2012).

In two very recent reports evidence of the involvement of other RTKs in AML offers the possibility of additional molecular targets: AXL was shown to activate FLT3 in AML (Park et al., 2013), and siRNA knockdown of Mer reduced colony formation and increased survival in mice (Lee-Sherick et al., 2013). (See Figure 2B for structures of the compounds discussed in this section.)

\section{Protein serine/threonine kinases}

$\boldsymbol{m}$ TOR. The PI3 kinase/AKT/mTOR pathway is activated in many acute leukemias, and promotes leukemia cell survival and proliferation (Barrett et al., 2012). Accordingly, mTOR inhibitors are being tested as single agents and in combination with existing chemotherapeutics. mTOR is a serine/threonine kinase, but the approach to inhibition of this target has generally differed from that of small-molecule active site-directed inhibitors employed against other protein kinases. Current clinical studies are focused on the macrolide natural product rapamycin and analogs, which inhibit mTOR once complexed with FK-binding protein 12 (FKBP12). Rapamycin (9) (sirolimus) is in a Phase II ALL trial in combination with methotrexate, and in Phase I studies in ALL and AML as a single agent. Temsirolimus (10), an analog of sirolimus, is being tested in combination with etoposide and cyclophosphamide in a Phase I ALL trial, and an ALL trial in combination with several other chemotherapeutic agents is due to start soon.
Everolimus (11), another analog of sirolimus, is marketed for several adult cancer indications. It is currently in a Phase I ALL trial in combination with induction chemotherapy. A promising alternative to macrolide inhibition of the mTOR-FKBP12 complex is the development of dual PI3 kinase/mTOR inhibitors (Martelli et al., 2012). The ATP-binding pockets in the catalytic sites of PI3 kinase and mTOR are structurally similar, allowing the development of compounds that inhibit both enzymes. The dual PI3 kinase/mTOR inhibitor NVP-BEZ235 (12) was originally developed for the treatment of solid tumors (Maira et al., 2008), but it has recently shown potent activity in ALL, and synergy with chemotherapeutic agents, even in glucocorticoid-resistant cells (Schult et al., 2012). (See Figure 2C for structures of the compounds discussed in this section.)

AKT. AKT is a serine/threonine kinase functionally connected with mTOR complexes that is a central component of signaling through RTKs such as FLT3 (Park et al., 2010). Therefore, AKT inhibition offers an approach to proliferative pathway suppression that is complementary to inhibition of FLT3 or mTOR described above. AKT inhibitors are being evaluated as single agents; MK2206 (13) is in Phase I trials in recurrent or refractory ALL and AML. However, their most promising use could be as potentiators of the efficacy of FLT3 inhibitors. Despite indisputable evidence that FLT3 is a key driver in AML, and the discovery of potent, selective inhibitors, the clinical effectiveness of FLT3 inhibitors has been modest. A significant reason for this appears to be that leukemia 
A. BCR-ABL inhibitors

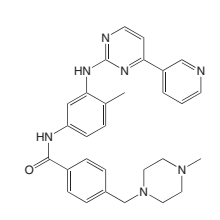

1. Imatinib

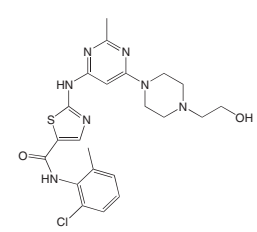

2. Dasatinib

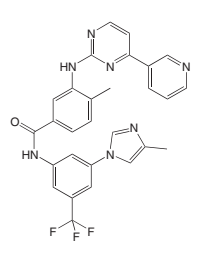

3. Nilotinib

B. FLT3 inhibitors

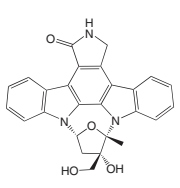

4. Lestaurtinib

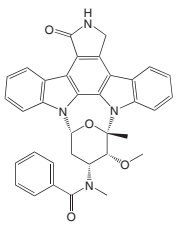

5. Midostaurin<smiles>CNC(=O)c1ccc(Oc2ccc(NC(=O)Nc3ccc(Cl)c(C(F)(F)F)c3)cc2)cc1</smiles>

6. Sorafenib

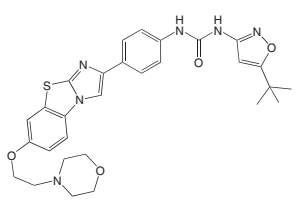

7. Quizartinib

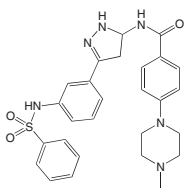

8. BPR1J-097

C. mTOR inhibitors

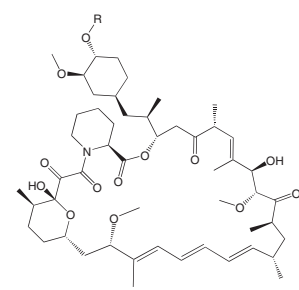

E. JAK 1/2 inhibitors<smiles>N#CCC(C1CCCC1)N1CCN(c2ncnc3[nH]cnc23)C1</smiles>

14. Ruxolitinib

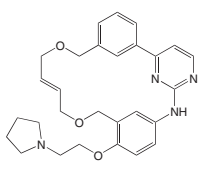

15. Pacritinib

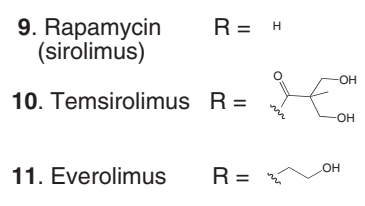

9. Rapamycin

11. Everolimus

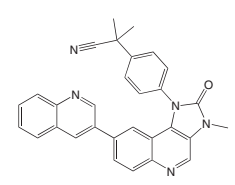

12. NVP-BEZ235
D. AKT inhibitor

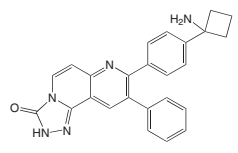

13. MK-2206
G. Proteasome inhibitor

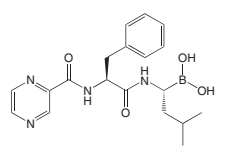

20. Bortezomib

F. Aurora kinase inhibitors

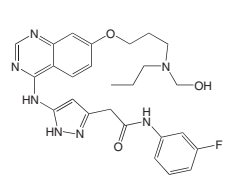

16. Barasertib

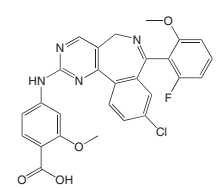

17. Alisertib

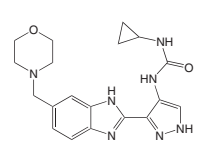

18. AT9283

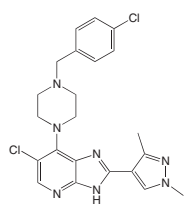

19. Compound $27 \mathrm{e}$

H. BCL-2 inhibitors

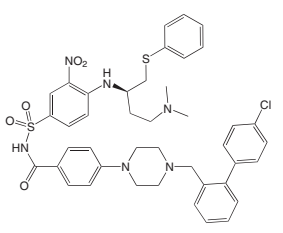

21. $\mathrm{ABT}-737$

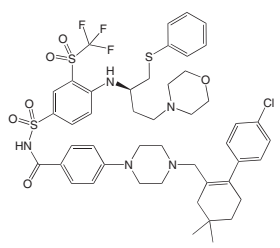

22. Navitoclax
FIGURE 2 | Compounds targeting inhibition of cell proliferation or induction of apoptosis. Numbers in bold type are used to refer to compounds in this figure from the main text, Figure 4, and Table 1. (A)
BCR-ABL inhibitors, (B) FLT3 inhibitors, (C) mTOR inhibitors, (D) AKT inhibitor, (E) JAK1/2 inhibitors, (F) aurora kinase inhibitors, (G) proteasome inhibitor, (H) BCL-2 antagonists. stem cells (LSCs) reside in the bone marrow, where they are protected from drug treatment. A high-throughput screen to test investigational drug combinations in a co-culture of FLT-positive AML and stromal cells found that MK-2206 (13) synergistically potentiated the cytotoxic effect of the FLT3 inhibitor midostaurin (5) (Weisberg et al., 2013).

An unexpected finding in the AKT pathway is that members of the FOXO family of transcription factors enforce differentiation 
A. DNA methyltransferase inhibitors

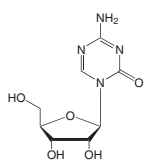

24. 5-Azacytidine

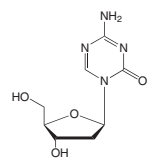

25. Decitabine

B. Histone deacetylase inhibitors

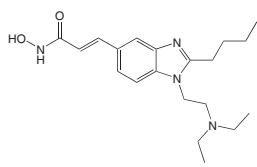

26. Pracinostat

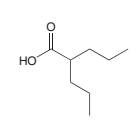

27. Valproic acid<smiles>CC(C)NC(=O)CCCCCCC(=O)Nc1ccccc1</smiles>

28. Vorinostat

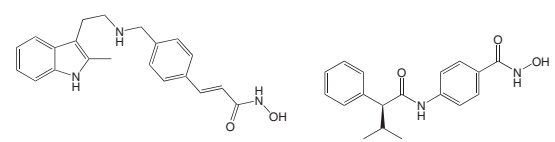

29. Panobinostat

30. AR-42

C. DOT1L inhibitors

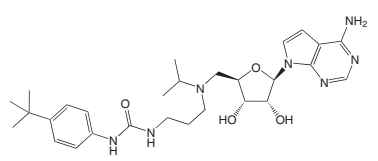

31. EPZ004777

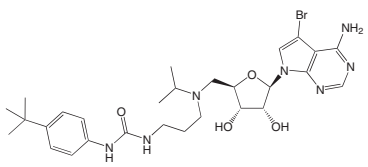

32. SGC0946

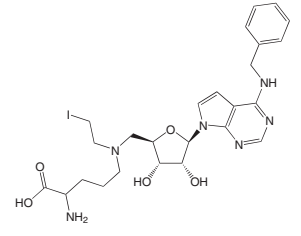

33
D. BRD4 inhibitors

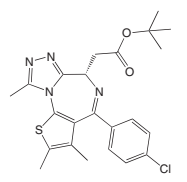

34. (+)-JQ1

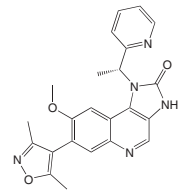

35. I-BET151
E. Menin-binding inhibitor

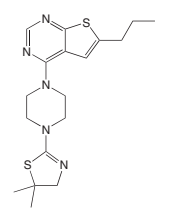

36. MI-2

F. CXR4 antagonist

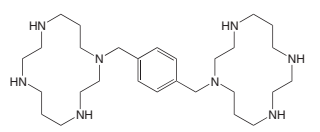

37. Plerixafor

FIGURE 3 | Compounds targeting transcription or stem cell homing. Numbers in bold type are used to refer to compounds in this figure from the main text, Figure 5, and Table 1. (A) DNA methyltransferase inhibitors, (B) histone deacetylase inhibitors, (C) DOT1L inhibitors, (D) BRD4 inhibitors, (E) Menin-binding inhibitor, (F) CXCR4 antagonist.

blockade in AML (Sykes et al., 2011). The FOXOs are usually considered to be tumor suppressors that are inhibited by AKT through serine/threonine phosphorylation. However, in approximately $40 \%$ of AML, AKT itself is repressed, and the FOXOs are elevated and found to be essential to maintenance of an undifferentiated state. Activation of AKT or deletion of the FOXOs caused myeloid maturation and apoptosis in AML cells, but this effect was countered by a resistance mechanism in which c-JUN was activated, so a combination of FOXO and JNK (c-JUN Nterminal kinase) inhibition may be an effective therapeutic strategy 


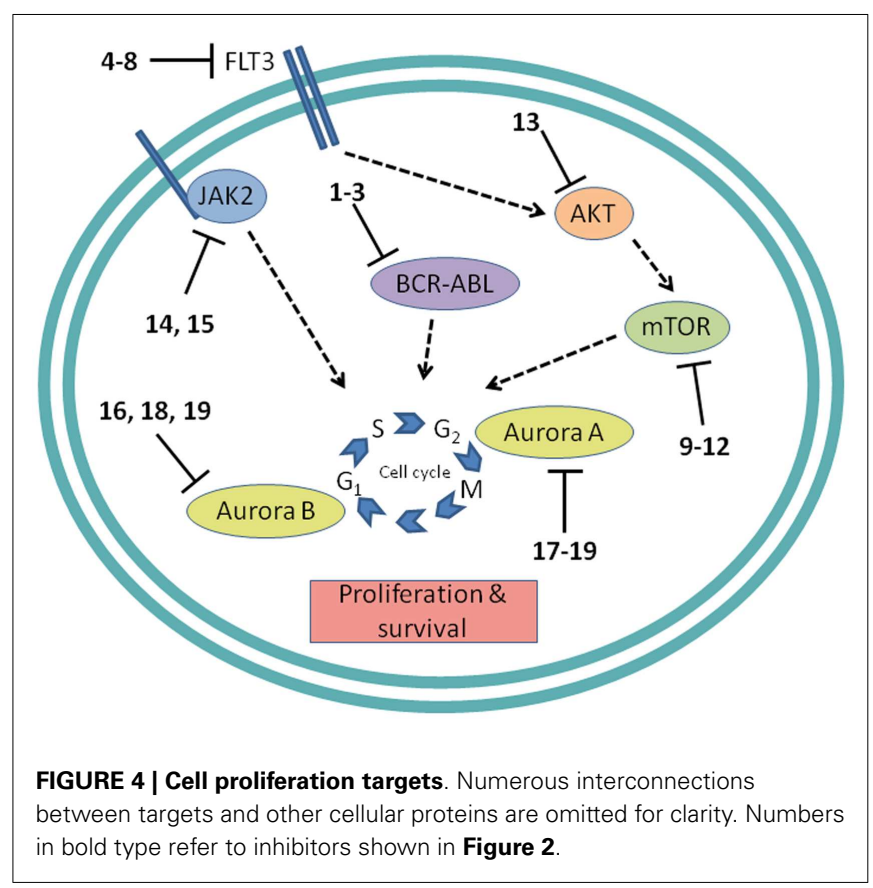

(Sykes et al., 2011). (See Figures 2B,D for structures of the compounds discussed in this section.)

$J A K \mathbf{1} / 2$. The JAK/STAT pathway is activated in certain high-risk leukemias, especially $\mathrm{Ph}^{+}$-like ALL, leading to cell proliferation and resistance to apoptosis (Maude et al., 2012). Activating mutations of JAK kinases are also present in AML (Daver and Cortes, 2012). A Phase I clinical trial is underway to test a selective JAK1/2 inhibitor, ruxolitinib (14). The aim is to select patients with refractory or relapsed ALL or AML harboring JAK mutations, although leukemia patient numbers may be limited because the trial also includes patients with solid tumors. JAK inhibitors may also be useful in combination with other targeted therapies. The JAK2/FLT3 inhibitor pacritinib (15) demonstrated synergy with the histone deacetylase (HDAC) inhibitor pracinostat (26) in mouse AML models (Novotny-Diermayr et al., 2012). This JAK2/HDAC inhibitor synergy may arise due to JAK2 possessing an epigenetic function; in addition to its role in activation of JAK-STAT signaling, JAK2 phosphorylates tyrosine 41 in histone 3 (H3Y41), leading to displacement of heterochromatin protein $1 \alpha$. JAK inhibitors were also found to potentiate the cytotoxicity of FLT3 inhibitors in a high-throughput screen of investigational drug combinations in a co-culture of AML and stromal cells, suggesting that JAK inhibitors may be effective in overcoming the drug resistance of AML residing in the bone marrow (Weisberg et al., 2012). In a related study, discussed in Section "AKT" above, the same research group observed synergy between AKT and FLT3 inhibition. (See Figures 2E and 3B for structures of the compounds discussed in this section.)

Aurora kinases. Aurora kinases A and B are serine/threonine kinases that play a key role in the control of mitosis. Overexpression of these enzymes has been observed in pediatric leukemia and is associated with a poor prognosis (Farag, 2011). Although both enzymes have generated interest as targets, short hairpin RNA knockdown, and corroboration using the selective aurora kinase $\mathrm{B}$ inhibitor barasertib (16) suggested that antiproliferative and proapoptotic effects are mediated predominantly through inhibition of aurora kinase B (Hartsink-Segers et al., 2013). These findings appear to be at odds with clinical progress to date with the selective aurora A inhibitor alisertib (17). Alisertib is currently in a Phase II trial that includes refractory and relapsed ALL and AML as well as pediatric solid tumors. Fragment-based drug discovery was used to develop AT9283 (18), an inhibitor of aurora kinases $\mathrm{A}$ and $\mathrm{B}$ and also JAK2. This compound was found to inhibit growth and survival of patient-derived leukemia cells, associated with a reduction in levels of phosphorylated FLT3 and inhibition of downstream effectors such as ERK and MEK (Jayanthan et al., 2013). On the basis of the encouraging pre-clinical results, AT9283 is being tested in relapsed and refractory ALL and AML in a Phase I trial in the UK. A potentially important development is the discovery of compounds that inhibit both FLT3 and aurora kinases; a dual FLT3/aurora kinase inhibitor known simply as compound 27e (19) may show enhanced clinical efficacy due to synergy between FLT3 and aurora kinase inhibition (Bavetsias et al., 2012). (See Figure 2F for structures of the compounds discussed in this section.)

\section{Proteasome}

Bortezomib (20) is a highly potent proteasome inhibitor that protects tumor suppressor proteins from degradation. It is approved and marketed for the treatment of multiple myeloma, but it also promises to be effective in combination with other targeted therapies and conventional chemotherapy in leukemia (Niewerth et al., 2013). Combination of bortezomib with the HDAC inhibitor valproic acid (27) was effective against B-cell precursor ALL in cell culture and mouse xenograft with or without simultaneous treatment with chemotherapeutic agents. Evidence suggests that the activity of the drug combination is mediated through modulation of NF- $\kappa \mathrm{B}$ activity, thereby promoting apoptosis (Bastian et al., 2013). A Phase I trial in pediatric ALL and AML demonstrated the effectiveness of bortezomib as a chemosensitizer in conjunction with chemotherapy, although not as a single agent (Horton et al., 2007). Bortezomib is currently being tested in a Phase III trial in AML, as well as in ALL in two Phase II combination trials, one with the HDAC inhibitor vorinostat (28, see also "Histone deacetylases") together with dexamethasone, and the other with combination chemotherapy. (See Figures 2G and 3B for structures of the compounds discussed in this section.)

\section{Anti-apoptotic protein BCL-2}

Inhibition of the anti-apoptotic protein BCL-2 sensitizes cancer cells to chemotherapy induced apoptosis (Fulda, 2009). In cell lines and mouse xenografts derived from ALL patients, the BCL2 antagonist ABT-737 (21) demonstrated synergistic cytotoxicity with standard chemotherapy (Kang et al., 2007). Furthermore, in the pediatric pre-clinical testing program the orally bioavailable BCL-2 antagonist navitoclax (22) (ABT-263) showed the greatest efficacy against ALL among all the cancer models tested (Lock et al., 2008). A recent study demonstrated cytotoxicity of the BCL2 antagonist obatoclax (23) in a broad range of patient-derived infant ALL cell lines, and synergistic cell killing in combination 
with chemotherapeutic agents (Urtishak et al., 2013). The clinical effectiveness of obatoclax combined with standard chemotherapy is being tested in a Phase I trial in ALL and AML. (See Figure 2H for structures of the compounds discussed in this section.)

\section{TRANSCRIPTION}

Inappropriate expression of specific genes caused by dysregulated epigenetic modification appears to be a hallmark of many of the most difficult to treat pediatric leukemias. Early work in this area was focused on inhibition of DNA methyltransferases and histone deacetylases (HDACs), due to the apparent role of these enzymes in preventing expression of key tumor suppressor genes. Much recent activity has been focused on histone methyltransferase, bromodomain, and menin inhibition to suppress transcriptional activation leading to elevated expression of specific oncogenes that block differentiation of hematopoietic progenitors (Figure 5). An epigenetic block of normal differentiation appears to be a key driver of pediatric leukemia harboring chromosomal rearrangements that lead to fusion proteins, notably MLL fusions and NUP98NSD1 (Deshpande et al., 2012; Hatlen et al., 2012; Popovic and Licht, 2012; Vu et al., 2013).

MLL fusions are the hallmark of an aggressive subtype of pediatric ALL and AML known as mixed lineage leukemia, associated with translocations of the MLL gene (Muntean and Hess, 2012). These $M L L$ rearrangements are especially prevalent in infant ALL, occurring in $80 \%$ of cases, and also in $75 \%$ of therapy-related AML. The 5-year survival rate for ALL without MLL rearrangement approaches $90 \%$; in stark contrast, infants with ALL harboring $M L L$ rearrangements have a very poor $40 \%$ survival rate (Robinson et al., 2009; Slany, 2009). The normal role of the MLL protein is to modulate transcriptional elongation through histone methylation. However, rearrangement of the MLL gene disrupts the function of MLL by replacement of its C-terminal methyltransferase domain with a fusion protein. Fifty such fusion partners are known, although 5 account for $80 \%$ of cases (Huret et al,, 2001; Meyer et al., 2006; Krivtsov and Armstrong, 2007). The protein complex recruited by the MLL fusion activates transcription of oncogenes critical for leukemic transformation, notably HOXA9 and MEIS1 (Ayton and Cleary, 2003; Faber et al., 2009; Mueller et al., 2009). Following early hematopoietic development,

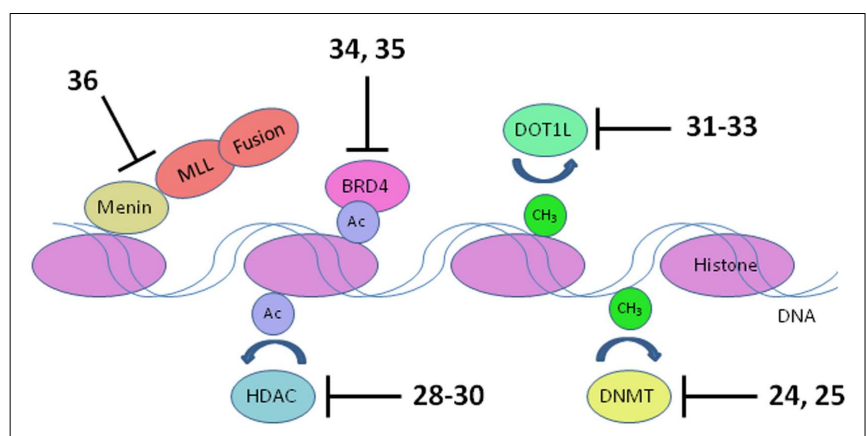

FIGURE 5 | Transcriptional targets. Numerous interconnections between targets and other proteins involved in transcriptional activation are omitted for clarity. HDAC, histone deacetylase; DNMT, DNA methyltransferase. Numbers in bold type refer to inhibitors shown in Figure $\mathbf{3}$ expression of HOXA9 and MEIS1 is normally suppressed to allow blood cell differentiation. Activated HOXA9 blocks differentiation of hematopoietic progenitor cells, which instead acquire stem celllike character and the capacity for unlimited self renewal (Somervaille and Cleary, 2010). Several components of the transcriptional activation complex in MLL-R leukemia are being targeted: menin, bromodomains, and the methyltransferase DOT1L (Figure 5).

The NUP98-NSD1 fusion protein occurs in a high-risk subtype of AML following rearrangement of the genes NUP98 (nucleoporin, 98-kd component of nuclear pore complex) and NSD1 (nuclear receptor-binding SET domain protein 1). Since the first case was identified 12 years ago (Jaju et al., 2001), it has become clear that these genetic lesions are often missed by routine karyotyping. A recent comprehensive study using reverse transcription polymerase chain reaction (RT-PCR) found NUP98-NSD1 in 4$5 \%$ of pediatric AML, associated with a grim 4-year event-free survival rate of $<10 \%$ (Hollink et al., 2011). NSD1 is a histone methyltransferase that regulates gene transcription through methylation of lysine 36 in histone 3 (H3K36) (Morishita and di Luccio, 2011; Wagner and Carpenter, 2012). The methyltransferase activity of NSD1 is retained in the NUP98-NSD1 fusion, and gives rise to abnormally high levels of H3K36 methylation, enforcing activation of transcription of oncogenes such as HOXA9. As in MLL-R leukemia, elevated expression of HOXA9 in AML harboring NUP98-NSD1 blocks differentiation of blood cell progenitors, leading them to acquire the capacity for unlimited self-renewal and malignant transformation (Wang et al., 2007). Abolition of the methyltransferase activity of NUP98-NSD1 by point mutation demonstrated its essential role; the level of H3K36 methylation at the HoxA9 locus was reduced, and mouse progenitor cells harboring NUP98-NSD1 underwent normal differentiation (Wang et al., 2007). Therefore, inhibition of the methyltransferase activity of NUP98-NSD1 may be a viable therapeutic strategy, although no inhibitors of this fusion have been reported to date.

\section{DNA methyltransferases}

Elevated levels of DNA methylation lead to impaired expression of tumor suppressor genes and other epigenetic changes that promote precancerous and cancerous conditions (Lyko and Brown, 2005). Two DNA methyltransferase inhibitors have been approved for the treatment of myelodysplastic syndrome: 5-azacytidine (24) and decitabine (25) (Fandy, 2009). These drugs have been evaluated in clinical trials in AML, and decitabine received European but not US approval in 2012 for treatment of adult AML. Two trials in pediatric AML are pending: a Phase II trial focused on maintenance therapy employing 5-azacytidine in combination with the immunomodulatory biologic sargramostim, and a Phase I trial of decitabine in combination with the HDAC inhibitor AR-42 (30, see 2.2.2). (See Figures 3A,B for structures of the compounds discussed in this section.)

\section{Histone deacetylases}

Acetylation of histones promotes transcription by increasing accessibility of chromatin and exposing acetylated lysine residues as key epigenetic markers that lead to recruitment of RNA polymerase. In the context of cancer, HDACs remove these acetyl modifications, blocking expression of key tumor suppressor genes. 
Following numerous trials of HDAC inhibitors, two compounds have been approved for the treatment of adult cancers (Giannini et al., 2012). Currently, pediatric leukemia trials are underway to test HDAC inhibitors as single agents and also in combination with DNA methyltransferase inhibitors (Mummery et al., 2011). Vorinostat (28) was the first HDAC inhibitor approved for clinical use. It is a relatively simple molecule containing a zinc-binding hydroxamic acid moiety that inhibits a broad spectrum of HDACs. It is in Phase II pediatric testing in ALL and AML. A Phase I trial in ALL and AML is also underway with panobinostat (29), another broad-spectrum HDAC inhibitor containing a hydroxamic acid group under development for various adult cancers. A Phase I trial in AML is due to start soon combining the DNA methyltransferase inhibitor decitabine (25) with the HDAC inhibitor AR-42 (30), which was reported to be superior to other broadspectrum HDAC inhibitors (Lucas et al., 2010). (See Figures 3A,B for structures of the compounds discussed in this section.)

\section{Histone methyltransferase DOT1L}

Compelling evidence links recruitment of the histone methyltransferase DOT1L to transcriptional activation of oncogenes such as HOXA9 in MLL-R leukemia (Bernt and Armstrong, 2011; Zhang et al., 2012). The enzymatic activity of the histone methyltransferase DOT1L has been shown to be essential for MLL-R leukemia in several studies. Conditional knockdown of Dot 11 in mice harboring the MLL-AF6 fusion inhibited leukemia progression (Deshpande et al., 2013), and the same group demonstrated that Dot1l knockout prevented initiation of leukemia harboring MLL-AF10 (Chen et al., 2012). An earlier study showed DOT1L to be essential for HOXA9 and MEIS1 expression and the resulting leukemia driven by MLL-AF9 (Nguyen et al., 2011). DOT1L knockdown has also been shown to induce apoptosis in cells transformed with a variety of MLL fusions (Chang et al., 2010). Therefore, efforts are underway to develop inhibitors of the enzymatic activity of DOT1L. DOT1L differs structurally from all other histone lysine methyltransferases (HKMTs) in that it does not possess a SET domain comprising the catalytic site. This structural uniqueness in the architecture of the catalytic site facilitates discovery of selective inhibitors. Furthermore, DOT1L is the only enzyme known to methylate lysine 79 on histone 3 (H3K79), reducing the possibility of activation of an alternative cellular pathway to circumvent a block to DOT1L-mediated methylation.

The most significant progress in the development of DOT1L inhibitors has been made using structure-based and mechanistically guided design based on the published X-ray crystallographic structure of the catalytic domain of the enzyme (Min et al., 2003). This approach led to EPZ004777 (31), a mimic of the methyl donor substrate $S$-adenosylmethionine (SAM) that inhibits DOT1L with high potency and selectivity. EPZ004777 displayed selective killing of MLL-R leukemia cell lines and suppressed expression of the HOXA9 and MEIS1 oncogenes, consistent with the proposed role of the enzyme target. Moreover, despite poor pharmacokinetic properties, 7-day continuous infusion of EPZ004777 resulted in a modest but significant increase in survival in a mouse model of engrafted MLL-R leukemia. The apparent uniqueness of DOT1L's normal role had earlier raised concerns that inhibitors would prove to be unacceptably toxic, but evidence with EZ004777 suggested otherwise (Daigle et al., 2011). Subsequently, the X-ray crystal structure of EPZ004777 bound to DOT1L was solved, and the structural insights were used to incorporate a bromine substituent in the adenine ring to give SGC0946 (32). Compared to EPZ004777, SGC0946 showed an improved $K_{\mathrm{D}}$ of $60 \mathrm{pM}$, increased residence time on the enzyme due to a slower dissociation rate, and improved cell permeability, leading to greater efficacy in reducing intracellular H3K79 methylation (Yu et al., 2012).

Identification of a hydrophobic pocket present in the SAM binding site of DOT1L but absent in all other histone methyltransferases led to the design of a SAM mimic with two key features: a benzyl moiety appended to the adenine ring to impart selective binding, and replacement of the $S$-methyl group with an $N$-iodoethyl group for irreversible covalent attachment to the $\varepsilon$-amino group in lysine 79 of histone 3 (33). This compound gave an $\mathrm{IC}_{50}$ of $110 \mathrm{nM}$ and displayed $>1000$-fold selectivity for DOT1L over other histone methyltransferases. However, the mechanism of action of the compound was not studied to determine whether it reacted with the lysine-containing substrate as predicted (Yao et al., 2011). A follow-up publication reported that 33 and other compounds containing a reactive $N$-iodoethyl group did not show the desired selective killing of MLL-R leukemia cells, so SAM analogs containing other $S$-methyl group replacements were synthesized. The most potent of these were analogs of EPZ004777 comprising the native adenine ring appended with $\mathrm{N}^{6}$ substituents. Although some cellular activity was observed in MLL-R leukemia cell lines, none of the compounds appeared to offer advantages over EPZ00477 itself (Anglin et al., 2012).

Recently the possibility has arisen that MLL-R leukemia may be targeted by blocking ubiquitinylation of histone $2 \mathrm{~B}$, preventing activation of DOT1L. Following a demonstration that the activity of DOT1L is markedly enhanced by interaction of the enzyme with ubiquitinylated histone 2B (McGinty et al., 2008, 2009), it has now been reported that proliferation of MLL-R leukemia cells was suppressed by knockdown of the ubiquitin ligase RNF20 that ubiquitinylates histone 2B (Wang et al., 2013). (See Figure 3C for structures of the compounds discussed in this section.)

\section{Bromodomains}

BRD4 is a member of the BET (bromodomain and extra-terminal domain) family of proteins that binds to acetylated lysine in histones via a structural motif known as a bromodomain. In several cancers including acute leukemia, the resulting activation of transcriptional elongation promotes the expression of growthpromoting oncogenes (Deshpande et al., 2012; Popovic and Licht, 2012). An siRNA screen in AML cells revealed that inhibition of BRD4 led to cell cycle arrest and apoptosis. Structure-based design based on the X-ray crystal structure of the bromodomain in BRD4 led to (+)-JQ1 (34), a potent and selective inhibitor of binding of acetylated lysine (Filippakopoulos et al., 2010). (+)JQ1 suppressed proliferation of AML cells in culture and also extended survival in a mouse model of AML (Zuber et al., 2011). Subsequently (+)-JQ1 was shown to be cytotoxic to B-cell ALL cell lines, especially those harboring rearrangements of CRLF2. CRLF2 heterodimerizes with the IL7 receptor (IL7R) and drives proliferation and resistance to apoptosis. Strikingly, the genes 
most strongly downregulated by (+)-JQ1 were MYC and IL7R (Ott et al., 2012). (+)-JQ1 also suppressed growth and induced apoptosis in primary cells from patients with freshly diagnosed and relapsed AML. Based on these promising results (+)-JQ1 will be advanced to clinical trials (Herrmann et al., 2012). Another bromodomain inhibitor, I-BET151 (35), optimized for selective binding to BRD3/4 and good in vivo pharmacokinetics, gave a promising increase in survival in two mouse models of MLL-R leukemia (Dawson et al., 2011). The role of BRD4 in activation of transcription became clearer and potentially more significant with the discovery that it possesses protein kinase activity. BRD4 phosphorylates serine 2 on RNA polymerase II and thereby promotes transcriptional initiation and elongation (Devaiah et al., 2012). (See Figure 3D for structures of the compounds discussed in this section.)

\section{Menin and other proteins interacting with MLL fusions}

Another approach to disruption of transcriptional activation in MLL-R leukemia is to inhibit the interaction of MLL and menin. Menin appears to be a central hub that interacts with MLL fusions as well as wild type MLL and various other proteins to promote leukemia (Thiel et al., 2012). High-throughput screening for inhibitors of binding of an MLL-derived peptide to menin identified hits that were optimized for potency, leading to MI-2 (36). MI-2 was shown to disrupt the intracellular interaction of menin and MLL-AF9 and arrest cell growth in MLL-R leukemia cells, albeit with rather modest potency in the low micromolar range. Moreover, MI-2 blocked the transforming ability of MLL-AF9, suppressed the expression of the HOXA9 and MEIS1 oncogenes, and induced hematopoietic differentiation. No animal data has been reported so far; the intention is to optimize the inhibitors further to enable assessment of their therapeutic potential (Grembecka et al., 2012).

In addition to menin, various transcription factors and other proteins interact with MLL fusions to form an activation complex that promotes transcriptional elongation (Slany, 2009). In principal, several protein-protein interactions in this complex could be viable targets for disruption. One interaction that has been validated as a target with a peptide, and is being screened for small-molecule inhibitors, is the binding of MLL-AF4 to the transcription factor AF9 (Watson et al., 2013). A direct AF4AF9 interaction has been demonstrated (Erfurth et al., 2004), and shown to be essential for the survival of leukemia cell lines containing MLL-AF4 and MLL-AF9 fusions (Srinivasan et al., 2004). Yeast two-hybrid assays identified the minimal amino acid sequence in

\section{REFERENCES}

Anglin, J. L., Deng, L., Yao, Y., Cai, G., Liu, Z., Jiang, H., et al. (2012). Synthesis and structureactivity relationship investigation of adenosine-containing inhibitors of histone methyltransferase DOT1L. J. Med. Chem. 55, 8066-8074. doi:10.1021/jm300917h

Attar, E. C. (2012). Get out and stay out. Blood 119, 3869-3870. doi:10.1182/blood2012-02-410357
Ayton, P. M., and Cleary, M. L. (2003). Transformation of myeloid progenitors by MLL oncoproteins is dependent on Hoxa7 and Hoxa9. Genes Dev. 17, 2298-2307. doi:10.1101/gad.1111603

Barr, R. D. (2010). Imatinib mesylate in children and adolescents with cancer. Pediatr. Blood Cancer 55, 18-25. doi:10.1002/pbc. 22484

Barrett, D., Brown, V. I., Grupp, S. A., and Teachey, D. T. (2012). Targeting

AF4 required for binding to AF9, and a cell-permeable peptide derived from this sequence was shown to disrupt intracellular AF4-AF9 binding. Moreover, this AF4-derived peptide killed cells harboring MLL-AF4 and MLL-AF9 fusions but had no effect on normal hematopoietic progenitor cells (Srinivasan et al., 2004). (See Figure 3E for structure of the compound discussed in this section.)

\section{CHEMOKINE RECEPTORS AND STEM CELL HOMING}

Antagonists of the chemokine receptor CXCR4 could be effective as chemosensitizing agents by preventing homing of LSCs to the bone marrow. LSCs residing in the bone marrow evade treatment by chemotherapeutic agents, resulting in resistance and relapse (Attar, 2012; Peled and Tavor, 2013). Plerixafor (37) is an antagonist of the CXCR4 chemokine receptor that has been FDA approved since 2008 for hematopoietic stem cell mobilization prior to transplantation in non-Hodgkin's lymphoma and multiple myeloma. Encouraging results were reported recently from a Phase I trial of plerixafor in combination with cytarabine and etoposide in adult AML (Uy et al., 2012) and a pediatric ALL and AML trial is now underway. A recent report (Sison et al., 2013) shows that CXCR4 antagonists may also synergize with other targeted therapies; in a mouse model of infant MLL-R ALL, plerixafor markedly enhanced the efficacy of the FLT3 inhibitor lestaurtinib (4). (See Figures $2 \mathrm{~B}$ and $3 \mathrm{~F}$ for structures of the compounds discussed in this section.)

\section{CONCLUDING REMARIKS}

Based on a steady increase in understanding of the cellular mechanisms operating in high-risk pediatric leukemias, there is an encouraging level of activity aimed at the discovery of targeted therapies. Some of the molecular targets, such as protein kinases, are already well established in adult cancers. In other cases, pediatric leukemia research has led to novel targets that had not previously attracted attention; a notable example is the histone methyltransferase DOT1L. Given the number and diversity of new chemical entities currently in pre-clinical and clinical development for high-risk pediatric ALL and AML, the prospects are good for significantly improved outcomes for children afflicted with these cancers.

\section{ACKNOWLEDGMENTS}

We thank E. Anders Kolb, M.D., for helpful discussions. Financial support was provided by the Nemours Foundation (to Andrew D. Napper) and a UNCF/Merck Postdoctoral Fellowship (to Venita G. Watson).

the PI3K/AKT/mTOR signaling axis in children with hematologic malignancies. Paediatr. Drugs 14, 299-316. doi:10.2165/11594740000000000-00000

Bastian, L., Hof, J., Pfau, M., Fichtner, I., Eckert, C., Henze, G., et al. (2013). Synergistic activity of bortezomib and HDACi in preclinical models of B-cell precursor acute lymphoblastic leukemia via modulation of p53, PI3K/AKT, and NF-kappaB. Clin. Cancer Res. 19, 1445-1457.
doi:10.1158/1078-0432.CCR-121511

Bavetsias, V., Crumpler, S., Sun, C., Avery, S., Atrash, B., Faisal, A., et al. (2012). Optimization of imidazo[4,5-b]pyridine-based

kinase inhibitors: identification of a dual FLT3/aurora kinase inhibitor as an orally bioavailable preclinical development candidate for the treatment of acute myeloid leukemia. J. Med. Chem. 55, 8721-8734. doi:10.1021/jm300952s 
Bernt, K. M., and Armstrong, S. A. (2011). Targeting epigenetic programs in MLLrearranged leukemias. Hematology Am. Soc. Hematol. Educ. Program 2011, 354-360. doi:10.1182/asheducation-

2011.1.354

Brandwein, J. M. (2011). Treatment of acute lymphoblastic leukemia in adolescents and young adults. Curr. Oncol. Rep. 13, 371-378. doi:10.1007/s11912-011-0185-9

Brown, P., Hunger, S. P., Smith, F. O., Carroll, W. L., and Reaman, G. H. (2009). Novel targeted drug therapies for the treatment of childhood acute leukemia. Expert Rev. Hematol. 2, 145. doi:10.1586/ ehm.09.1

Brown, P., Levis, M., McIntyre, E., Griesemer, M., and Small, D. (2006). Combinations of the FLT3 inhibitor CEP-701 and chemotherapy synergistically kill infant and childhood MLL-rearranged ALL cells in a sequence-dependent manner. Leukemia 20, 1368-1376. doi:10.1038/sj.leu.2404277

Chang, M. J., Wu, H., Achille, N. J., Reisenauer, M. R., Chou, C. W., Zeleznik-Le, N. J., et al. (2010). Histone $\mathrm{H} 3$ lysine 79 methyltransferase Dot1 is required for immortalization by MLL oncogenes. Cancer Res. 70, 10234-10242. doi:10.1158/00085472.CAN-10-3294

Chen, L., Deshpande, A. J., Banka, D., Bernt, K. M., Dias, S., Buske, C., et al. (2012). Abrogation of MLLAF10 and CALM-AF10-mediated transformation through genetic inactivation or pharmacological inhibition of the H3K79 methyltransferase Dot1l. Leukemia 27, 813-822. doi:10.1038/leu.2012.327

Cortes, J. E., Kantarjian, H., Shah, N. P., Bixby, D., Mauro, M. J., Flinn, I., et al. (2012). Ponatinib in refractory Philadelphia chromosome-positive leukemias. $N$. Engl. J. Med. 367, 2075-2088. doi:10.1056/NEJMoa1205127

Daigle, S. R., Olhava, E. J., Therkelsen, C. A., Majer, C. R., Sneeringer, C. J., Song, J., et al. (2011). Selective killing of mixed lineage leukemia cells by a potent small-molecule DOT1L inhibitor. Cancer Cell 20, 53-65. doi:10.1016/j.ccr.2011.06.009

Daver, N., and Cortes, J. (2012). Molecular targeted therapy in acute myeloid leukemia. Hematology 17(Suppl. 1), S59-S62. doi:10.1179/102453312X133361691 55619

Dawson, M. A., Prinjha, R. K., Dittmann, A., Giotopoulos, G.,
Bantscheff, M., Chan, W. I., et al. (2011). Inhibition of BET recruitment to chromatin as an effective treatment for MLL-fusion leukaemia. Nature 478, 529-533. doi:10.1038/nature10509

Deshpande, A. J., Bradner, J., and Armstrong, S. A. (2012). Chromatin modifications as therapeutic targets in MLL-rearranged leukemia. Trends Immunol. 33, 563-570. doi:10.1016/j.it.2012.06.002

Deshpande, A. J., Chen, L., Fazio, M., Sinha, A. U., Bernt, K. M., Banka, D., et al. (2013). Leukemic transformation by the MLLAF6 fusion oncogene requires the H3K79 methyltransferase Dot1l. Blood 121, 2533-2541. doi:10.1182/blood-2012-11-465120

Devaiah, B. N., Lewis, B. A., Cherman, N., Hewitt, M. C., Albrecht, B. K., Robey, P. G., et al. (2012). BRD4 is an atypical kinase that phosphorylates serine2 of the RNA polymerase II carboxyterminal domain. Proc. Natl. Acad. Sci. U.S.A. 109, 6927-6932. doi:10.1073/pnas.1120422109

Erfurth, F., Hemenway, C. S., De Erkenez, A. C., and Domer, P. H. (2004). MLL fusion partners AF4 and AF9 interact at subnuclear foci. Leukemia 18, 92-102. doi:10.1038/sj.leu.2403200

Faber, J., Krivtsov, A. V., Stubbs, M. C., Wright, R., Davis, T. N., Van Den Heuvel-Eibrink, M., et al. (2009). HOXA9 is required for survival in human MLL-rearranged acute leukemias. Blood 113, 2375-2385. doi:10.1182/blood-2007-09-113597

Fandy, T. E. (2009). Development of DNA methyltransferase inhibitors for the treatment of neoplastic diseases. Curr. Med. Chem. 16, 2075-2085. doi:10.2174/092986709788612738

Farag, S. S. (2011). The potential role of aurora kinase inhibitors in haematological malignancies. Br. J. Haematol. 155, 561-579. doi:10.1111/j.13652141.2011.08898.x

Filippakopoulos, P., Qi, J., Picaud, S., Shen, Y., Smith, W. B., Fedorov, O., et al. (2010). Selective inhibition of BET bromodomains. Nature 468, 1067-1073. doi:10.1038/nature09504

Food and Drug Administration. (2013). FDA Approves Gleevec for Children with Acute Lymphoblastic Leukemia. Available at: http://www.fda.gov/NewsEvents/ Newsroom/PressAnnouncements/ ucm336868.htm [accessed March $17,2013]$
Fulda, S. (2009). Exploiting apoptosis pathways for the treatment of pediatric cancers. Pediatr. Blood Cancer 53, 533-536. doi:10.1002/pbc.21922

Giannini, G., Cabri, W., Fattorusso C., and Rodriquez, M. (2012). Histone deacetylase inhibitors in the treatment of cancer: overview and perspectives. Future Med. Chem. 4, 1439-1460. doi:10.4155/fmc. 12.80

Grembecka, J., He, S., Shi, A., Purohit, T., Muntean, A. G., Sorenson, R. J., et al. (2012). Menin-MLL inhibitors reverse oncogenic activity of MLL fusion proteins in leukemia. Nat. Chem. Biol. 8, 277-284 doi:10.1038/nchembio.773

Grunwald, M. R., and Levis, M. J. (2013). FLT3 inhibitors for acute myeloid leukemia: a review of their efficacy and mechanisms of resistance. Int. J. Hematol. 97, 683-694. doi:10.1007/s12185-013-1334-8

Hartsink-Segers, S. A., Zwaan, C. M., Exalto, C., Luijendijk, M. W., Calvert, V. S., Petricoin, E. F., et al. (2013). Aurora kinases in childhood acute leukemia: the promise of aurora $B$ as therapeutic target. Leukemia 27 , 560-568. doi:10.1038/leu.2012.256

Hatlen, M. A., Wang, L., and Nimer, S. D. (2012). AML1-ETO driven acute leukemia: insights into pathogenesis and potential therapeutic approaches. Front. Med. 6, 248-262. doi:10.1007/s11684-012-0206-6

Herrmann, H., Blatt, K., Shi, J., Gleixner, K. V., Cerny-Reiterer, S., Mullauer, L., et al. (2012). Small-molecule inhibition of BRD4 as a new potent approach to eliminate leukemic stem- and progenitor cells in acute myeloid leukemia AML. Oncotarget 3, 1588-1599.

Hollink, I. H., van den Heuvel-Eibrink, M. M., Arentsen-Peters, S. T. Pratcorona, M., Abbas, S., Kuipers, J. E., et al. (2011). NUP98/NSD1 characterizes a novel poor prognostic group in acute myeloid leukemia with a distinct HOX gene expression pattern. Blood 118, 3645-3656. doi:10.1182/blood-2011-04-34 6643

Horton, T. M., Pati, D., Plon, S. E., Thompson, P. A., Bomgaars, L. R., Adamson, P. C., et al. (2007). A phase 1 study of the proteasome inhibitor bortezomib in pediatric patients with refractory leukemia: a children's oncology group study. Clin. Cancer Res. 13, 1516-1522. doi:10.1158/10780432.CCR-06-2173

Hunger, S. P. (2011). Tyrosine kinase inhibitor use in pediatric Philadelphia chromosome-positive acute lymphoblastic anemia. Hematology
Am. Soc. Hematol. Educ. Program 2011, 361-365. doi:10. 1182/asheducation-2011.1.361

Huret, J. L., Dessen, P., and Bernheim, A. (2001). An atlas of chromosomes in hematological malignancies. Example: 11q23 and MLL partners. Leukemia 15, 987-989. doi:10.1038/sj.leu.2402135

Jaju, R. J., Fidler, C., Haas, O. A., Strickson, A. J., Watkins, F., Clark, K., et al. (2001). A novel gene, NSD1, is fused to NUP98 in the $\mathrm{t}(5 ; 11)(\mathrm{q} 35 ; \mathrm{p} 15.5)$ in de novo childhood acute myeloid leukemia. Blood 98, 1264-1267. doi:10.1182/blood.V98.4.1264

Jayanthan, A., Cooper, T. M., Hoeksema, K. A., Lotfi, S., Woldum, E. Lewis, V. A., et al. (2013). Occurrence and modulation of therapeutic targets of aurora kinase inhibition in pediatric acute leukemia cells. Leuk. Lymphoma 54, 1505-1516. doi:10.3109/10428194.2012.752079

Kampa-Schittenhelm, K. M., Heinrich, M. C., Akmut, F., Dohner, H. Dohner, K., and Schittenhelm, M. M. (2013). Quizartinib (AC220) is a potent second generation class III tyrosine kinase inhibitor that displays a distinct inhibition profile against mutant-FLT3, -PDGFRA and -KIT isoforms. Mol. Cancer 12 19. doi:10.1186/1476-4598-12-19

Kang, M. H., Kang, Y. H., Szymanska, B., Wilczynska-Kalak, U., Sheard, M. A., Harned, T. M., et al. (2007). Activity of vincristine, L-ASP, and dexamethasone against acute lymphoblastic leukemia is enhanced by the $\mathrm{BH} 3$-mimetic ABT-737 in vitro and in vivo. Blood 110, 2057-2066. doi:10.1182/blood-2007-03-080325

Kersey, J. H. (1997). Fifty years of studies of the biology and therapy of childhood leukemia. Blood 90, 4243-4251.

Krivtsov, A. V., and Armstrong, S. A. (2007). MLL translocations, histone modifications and leukaemia stemcell development. Nat. Rev. Cancer 7, 823-833. doi:10.1038/nrc2253

Kurmasheva, R. T., and Houghton, P. J. (2007). Pediatric oncology. Curr. Opin. Chem. Biol. 11, 424-432. doi:10.1016/j.cbpa.2007.05.037

Lee-Sherick, A. B., Eisenman, K. M., Sather, S., McGranahan, A. Armistead, P. M., McGary, C. S., et al. (2013). Aberrant Mer receptor tyrosine kinase expression contributes to leukemogenesis in acute myeloid leukemia. Oncogene. doi:10.1038/onc.2013.40. [Epub ahead of print].

Lin, W. H., Jiaang, W. T., Chen, C. W., Yen, K. J., Hsieh, S. Y., Yen, S. C., et al. (2012). BPR1J-097, a 
novel FLT3 kinase inhibitor, exerts potent inhibitory activity against AML. Br. J. Cancer 106, 475-481. doi:10.1038/bjc.2011.564

Lock, R., Carol, H., Houghton, P. J., Morton, C. L., Kolb, E. A., Gorlick, R., et al. (2008). Initial testing (stage 1) of the $\mathrm{BH} 3$ mimetic $\mathrm{ABT}-263$ by the pediatric preclinical testing program. Pediatr. Blood Cancer 50, 1181-1189. doi:10.1002/pbc.21433

Lucas, D. M., Alinari, L., West, D. A., Davis, M. E., Edwards, R. B., Johnson, A. J., et al. (2010). The novel deacetylase inhibitor AR42 demonstrates pre-clinical activity in B-cell malignancies in vitro and in vivo. PLoS ONE 5:e10941. doi:10.1371/journal.pone.0010941

Lyko, F., and Brown, R. (2005). DNA methyltransferase inhibitors and the development of epigenetic cancer therapies. J. Natl. Cancer Inst. 97, 1498-1506. doi:10.1093/jnci/dji311

Mackall, C. L. (2011). In search of targeted therapies for childhood cancer. Front. Oncol. 1:18. doi:10.3389/fonc.2011.00018

Maira, S. M., Stauffer, F., Brueggen, J., Furet, P., Schnell, C., Fritsch, C., et al. (2008). Identification and characterization of NVP-BEZ235, a new orally available dual phosphatidylinositol 3-kinase/mammalian target of rapamycin inhibitor with potent in vivo antitumor activity. Mol. Cancer Ther. 7, 1851-1863. doi:10.1158/ 1535-7163.MCT-08-0017

Martelli, A. M., Chiarini, F., Evangelisti, C., Cappellini, A., Buontempo, F., Bressanin, D., et al. (2012). Two hits are better than one: targeting both phosphatidylinositol 3-kinase and mammalian target of rapamycin as a therapeutic strategy for acute leukemia treatment. Oncotarget 3, 371-394.

Maude, S. L., Tasian, S. K., Vincent, T., Hall, J. W., Sheen, C., Roberts, K. G., et al. (2012). Targeting JAK $1 / 2$ and $\mathrm{mTOR}$ in murine xenograft models of $\mathrm{Ph}$-like acute lymphoblastic leukemia. Blood 120, 3510-3518. doi:10.1182/blood-2012-03-415448

McGinty, R. K., Kim, J., Chatterjee, C., Roeder, R. G., and Muir, T. W. (2008). Chemically ubiquitylated histone $\mathrm{H} 2 \mathrm{~B}$ stimulates hDot1L-mediated intranucleosomal methylation. Nature 453, 812-816. doi:10.1038/nature06906

McGinty, R. K., Kohn, M., Chatterjee, C., Chiang, K. P., Pratt, M. R., and Muir, T. W. (2009). Structure-activity analysis of semisynthetic nucleosomes: mechanistic insights into the stimulation of Dot1L by ubiquitylated histone
H2B. ACS Chem. Biol. 4, 958-968. doi:10.1021/cb9002255

Meyer, C., Schneider, B., Jakob, S., Strehl, S., Attarbaschi, A., Schnittger, S., et al. (2006). The MLL recombinome of acute leukemias. Leukemia 20, 777-784. doi:10.1038/sj.leu.2404150

Min, J., Feng, Q., Li, Z., Zhang, Y., and Xu, R. M. (2003). Structure of the catalytic domain of human DOT1L, a non-SET domain nucleosomal histone methyltransferase. Cell 112, 711-723. doi:10.1016/S00928674(03)00114-4

Morishita, M., and di Luccio, E. (2011). Cancers and the NSD family of histone lysine methyltransferases. Biochim. Biophys. Acta 1816, 158-163. doi:10.1016/j.bbcan.2011.05.004

Mueller, D., Garcia-Cuellar, M. P., Bach, C., Buhl, S., Maethner, E., and Slany, R. K. (2009). Misguided transcriptional elongation causes mixed lineage leukemia. PLoS Biol. 7:e1000249. doi:10.1371/journal.pbio.1000249

Mummery, A., Narendran, A., and Lee, K. Y. (2011). Targeting epigenetics through histone deacetylase inhibitors in acute lymphoblastic leukemia. Curr. Cancer Drug Targets 11, 882-893. doi:10.2174/156800911796798922

Muntean, A. G., and Hess, J. L. (2012). The pathogenesis of mixedlineage leukemia. Annu. Rev. Pathol. 7, 283-301. doi:10.1146/annurevpathol-011811-132434

National Cancer Institute. (2010). SEER (Surveillance, Epidemiology, and End Results) Statistics Review, 1975-2007.

National Cancer Institute. (2013). Clinical Trials. Available at: http://www.cancer.gov/clinicaltrials [accessed March 17, 2013].

Nguyen, A. T., Taranova, O., He, J., and Zhang, Y. (2011). DOT1L, the H3K79 methyltransferase, is required for MLL-AF9-mediated leukemogenesis. Blood 117, 6912-6922. doi:10.1182/blood-2011-02-334359

Niewerth, D., Dingjan, I., Cloos, J., Jansen, G., and Kaspers, G. (2013). Proteasome inhibitors in acute leukemia. Expert Rev. Anticancer Ther. 13, 327-337. doi:10.1586/era.13.4

Novotny-Diermayr, V., Hart, S., Goh, K. C., Cheong, A., Ong, L. C., Hentze, H., et al. (2012). The oral HDAC inhibitor pracinostat (SB939) is efficacious and synergistic with the JAK2 inhibitor pacritinib (SB1518) in preclinical models of AML. Blood Cancer J. 2, e69. doi:10.1038/bcj.2012.14
Ott, C. J., Kopp, N., Bird, L., Paranal, R. M., Qi, J., Bowman, T., et al. (2012). BET bromodomain inhibition targets both c-Myc and IL7R in high-risk acute lymphoblastic leukemia. Blood 120, 2843-2852. doi:10.1182/blood-2012-02-413021

Park, I. K., Mishra, A., Chandler, J., Whitman, S. P., Marcucci, G., and Caligiuri, M. A. (2013). Inhibition of the receptor tyrosine kinase Axl impedes activation of the FLT3 internal tandem duplication in human acute myeloid leukemia: implications for $\mathrm{Axl}$ as a potential therapeutic target. Blood 121, 2064-2073. doi:10.1182/ blood-2012-07-444018

Park, S., Chapuis, N., Tamburini, J., Bardet, V., Cornillet-Lefebvre, P., Willems, L., et al. (2010). Role of the PI3K/AKT and mTOR signaling pathways in acute myeloid leukemia. Haematologica 95, 819-828. doi:10.3324/haematol.2009.013797

Peled, A., and Tavor, S. (2013). Role of CXCR4 in the pathogenesis of acute myeloid leukemia. Theranostics 3 , 34-39. doi:10.7150/thno.5150

Popovic, R., and Licht, J. D. (2012). Emerging epigenetic targets and therapies in cancer medicine. Cancer Discov. 2, 405-413. doi:10.1158/2159-8290.CD-120076

Pui, C. H., Carroll, W. L., Meshinchi, S., and Arceci, R. J. (2011a). Biology, risk stratification, and therapy of pediatric acute leukemias: an update. J. Clin. Oncol. 29, 551-565. doi:10.1200/JCO.2010.30.7405

Pui, C. H., Gajjar, A. J., Kane, J. R., Qaddoumi, I. A., and Pappo, A. S. (2011b). Challenging issues in pediatric oncology. Nat. Rev. Clin. Oncol. 8, 540-549. doi:10.1038/nrclinonc.2011.95

Robinson, B.W., Devidas, M., Carroll, A.J., Harvey, R.C., Heerema, N.A., Willman, C.L., et al. (2009). "Specific MLL partner genes in infant acute lymphoblastic leukemia (ALL) associated with outcome are linked to age and white blood cell count (WBC) at diagnosis: a report on the Children's Oncology Group (COG) P9407 trial," in American Society of Hematology Annual Meeting and Exposition, New Orleans, LA.

Schult, C., Dahlhaus, M., Glass, A., Fischer, K., Lange, S., Freund, M., et al. (2012). The dual kinase inhibitor NVP-BEZ235 in combination with cytotoxic drugs exerts anti-proliferative activity towards acute lymphoblastic leukemia cells. Anticancer Res. 32, 463-474.
Schultz, K. R., Bowman, W. P., Aledo, A., Slayton, W. B., Sather, H., Devidas, M., et al. (2009). Improved early event-free survival with imatinib in Philadelphia chromosome-positive acute lymphoblastic leukemia: a children's oncology group study. J. Clin. Oncol. 27, 5175-5181. doi:10.1200/JCO.2008.21.2514

Sexauer, A., Perl, A., Yang, X., Borowitz, M., Gocke, C., Rajkhowa, T., et al. (2012). Terminal myeloid differentiation in vivo is induced by FLT3 inhibition in FLT3/ITD AML. Blood 120, 4205-4214. doi:10.1182/blood2012-01-402545

Sison, E. A., Rau, R. E., McIntyre, E., Li, L., Small, D., and Brown, P. (2013). MLL-rearranged acute lymphoblastic leukaemia stem cell interactions with bone marrow stroma promote survival and therapeutic resistance that can be overcome with CXCR4 antagonism. Br. J. Haematol. 160, 785-797. doi:10.1111/bjh.12205

Slany, R. K. (2009). The molecular biology of mixed lineage leukemia. Haematologica 94, 984-993. doi:10.3324/haematol.2008.002436

Somervaille, T. C., and Cleary, M. L. (2010). Grist for the MLL: how do MLL oncogenic fusion proteins generate leukemia stem cells? Int. J. Hematol. 91, 735-741. doi:10.1007/s12185-010-0579-8

Srinivasan, R. S., Nesbit, J. B., Marrero, L., Erfurth, F., Larussa, V. F., and Hemenway, C. S. (2004). The synthetic peptide PFWT disrupts AF4-AF9 protein complexes and induces apoptosis in $\mathrm{t}(4 ; 11)$ leukemia cells. Leukemia 18, 1364-1372. doi:10.1038/sj.leu.2403415

Stubbs, M. C., and Armstrong, S. A. (2007). FLT3 as a therapeutic target in childhood acute leukemia. Curr. Drug Targets 8, 703-714. doi:10.2174/138945007780830782

Swords, R., Freeman, C., and Giles, F. (2012). Targeting the FMS-like tyrosine kinase 3 in acute myeloid leukemia. Leukemia 26, 2176-2185. doi:10.1038/leu.2012.114

Sykes, S. M., Lane, S. W., Bullinger, L., Kalaitzidis, D., Yusuf, R., Saez, B., et al. (2011). AKT/FOXO signaling enforces reversible differentiation blockade in myeloid leukemias. Cell 146, 697-708. doi:10.1016/j.cell.2011.07.032

Thiel, A. T., Huang, J., Lei, M., and Hua, X. (2012). Menin as a hub controlling mixed lineage leukemia. Bioessays 34, 771-780. doi:10.1002/bies.201200007

Urtishak, K. A., Edwards, A. Y., Wang, L. S., Hudome, A., Robinson, 
B. W., Barrett, J. S., et al. (2013). Potent obatoclax cytotoxicity and activation of triple death mode killing across infant acute lymphoblastic leukemia (ALL). Blood. 121, 2689-2703. doi:10.1182/blood2012-04-425033

Uy, G. L., Rettig, M. P., Motabi, I. H., McFarland, K., Trinkaus, K. M., Hladnik, L. M., et al. (2012). A phase $1 / 2$ study of chemosensitization with the CXCR4 antagonist plerixafor in relapsed or refractory acute myeloid leukemia. Blood 119, 3917-3924. doi:10.1182/ blood-2011-10-383406

Vu, L. P., Luciani, L., and Nimer, S. D. (2013). Histone-modifying enzymes: their role in the pathogenesis of acute leukemia and their therapeutic potential. Int. J. Hematol. 97, 198-209. doi:10.1007/s12185012-1247-y

Wagner, E. J., and Carpenter, P. B. (2012). Understanding the language of Lys36 methylation at histone $\mathrm{H} 3$. Nat. Rev. Mol. Cell Biol. 13, 115-126. doi:10.1038/nrm3274

Wang, E., Kawaoka, S., Yu, M., Shi, J., Ni, T., Yang, W., et al. (2013). Histone H2B ubiquitin ligase RNF20 is required for MLLrearranged leukemia. Proc. Natl. Acad. Sci. U.S.A. 110, 3901-3906. doi:10.1073/pnas.1301045110

Wang, G. G., Cai, L., Pasillas, M. P., and Kamps, M. P. (2007). NUP98-NSD1 links H3K36 methylation to HoxA gene activation and leukaemogenesis. Nat. Cell Biol. 9, 804-812. doi:10.1038/ncb1608

Watson, V. G., Drake, K. M., Peng, Y., and Napper, A. D. (2013). Development of a high-throughput screening-compatible assay for the discovery of inhibitors of the AF4AF9 interaction using alphascreen technology. Assay Drug Dev. Technol. 11, 253-268. doi:10.1089/ adt.2012.495

Weisberg, E., Liu, Q., Nelson, E., Kung, A. L., Christie, A. L., Bronson, R., et al. (2012). Using combination therapy to override stromal-mediated chemoresistance in mutant FLT3-positive AML: synergism between FLT3 inhibitors, dasatinib/multi-targeted inhibitors and JAK inhibitors. Leukemia 26, 2233-2244. doi:10.1038/leu.2012.96 Weisberg, E., Liu, Q., Zhang, X., Nelson, E., Sattler, M., Liu, F., et al.
(2013). Selective Akt inhibitors synergize with tyrosine kinase inhibitors and effectively override stromaassociated cytoprotection of mutant FLT3-positive AML cells. PLoS ONE 8:e56473. doi:10.1371/journal.pone. 0056473

Yao, Y., Chen, P., Diao, J., Cheng, G., Deng, L., Anglin, J. L., et al. (2011). Selective inhibitors of histone methyltransferase DOT1L: design, synthesis, and crystallographic studies. J. Am. Chem. Soc. 133, 16746-16749. doi:10.1021/ja206312b

Yu, W., Chory, E. J., Wernimont, A K., Tempel, W., Scopton, A., Federation, A., et al. (2012). Catalytic site remodelling of the DOT1L methyltransferase by selective inhibitors. Nat. Commun. 3 , 1288. doi:10.1038/ncomms2304

Zhang, Y., Chen, A., Yan, X. M., and Huang, G. (2012). Disordered epigenetic regulation in MLLrelated leukemia. Int. J. Hematol. 96, 428-437. doi:10.1007/s12185012-1180-0

Zuber, J., Shi, J., Wang, E., Rappaport, A. R., Herrmann, H., Sison, E. A., et al. (2011). RNAi screen identifies Brd4 as a therapeutic target in acute myeloid leukaemia. Nature 478, 524-528. doi:10.1038/nature 10334

Conflict of Interest Statement: The authors declare that the research was conducted in the absence of any commercial or financial relationships that could be construed as a potential conflict of interest.

Received: 27 March 2013; accepted: 13 June 2013; published online: 08 July 2013. Citation: Napper AD and Watson VG (2013) Targeted drug discovery for pediatric leukemia. Front. Oncol. 3:170. doi: 10.3389/fonc. 2013.00170

This article was submitted to Frontiers in Pediatric Oncology, a specialty of Frontiers in Oncology.

Copyright (c) 2013 Napper and Watson. This is an open-access article distributed under the terms of the Creative Commons Attribution License, which permits use, distribution and reproduction in other forums, provided the original authors and source are credited and subject to any copyright notices concerning any third-party graphics etc. 